Atıf için / For Citation: Y.A. Üncü, H. Özdoğan, "Mamografi sistemlerinde ilgi alanı, türev ve ince gruplama seçimlerinin modülasyon transfer fonksiyonunun üzerine etkileri”, Süleyman Demirel Üniversitesi Fen Edebiyat Fakültesi Fen Dergisi, 15(1), 23-35, 2020.

\title{
Mamografi Sistemlerinde İlgi Alanı, Türev ve İnce Gruplama Seçimlerinin Modülasyon Transfer Fonksiyonunun Üzerine Etkileri
}

\author{
Yiğit Ali ÜNCÜ'1,*, Hasan ÖZDOĞAN ${ }^{1,2}$ \\ ${ }^{1}$ Akdeniz Üniversitesi, Tıp Fakültesi, Biyofizik Anabilim Dalı, Antalya, Türkiye \\ ${ }^{2}$ Antalya Bilim Üniversitesi, Meslek Yüksekokulu, Tıbbi Görüntüleme Teknikleri Programı, Antalya, \\ Türkiye \\ *yazışılan yazar e-posta: yuncu@akdeniz.edu.tr
}

(Alınış / Received: 28.11.2019, Kabul / Accepted: 14.01.2020, Yayımlanma / Published: 31.05.2020)

Özet: $\mathrm{Bu}$ çalışmada, mamografi sisteminin görüntü kalitesi matematiksel yöntemler ile ölçülmüştür. Mamografi sistemlerinde performans ölçümleri için uygulanan yeni yöntemler, bu sistemlerin görüntü kalitesinin sayısal olarak değerlendirilmesinde kullanılmıştır. Görüntüleme kalitesinin sayısal değerlendirilmesi, görsel değerlendirmelere göre daha objektif sonuçlar verdiğinden çalışma kapsamında sayısal değerlendirmeler üzerinde durulmuştur. Modülasyon transfer fonksiyonu (MTF) hesaplanmasında kenar görüntüleme metodu kullanılmış ve bu metodun kullanımında açı hesaplamaları yapılmıștır. Farklı ilgi alan seçimlerinde (ROI) kenar dağglım fonksiyonlarının (ESF) nasıl değiştiği gözlemlenmiş, farklı türev seçimlerinin çizgisel dağ 1 lım fonksiyonu (LSF) ve MTF üzerine etkisi ve ince gruplama (rebinning) işleminin ESF, LSF, MTF üzerine etkileri incelenmiştir. Bütün bu yöntemlerin hesaplamaları, MATLAB programı kullanılarak tasarlanıp gerçekleştirilmiştir.

Anahtar kelimeler: Mamografi sistemleri, Görüntü kalitesi değerlendirme, Modülasyon transfer fonksiyonu, MATLAB

\section{The Effects of Region of Interest, Differentiation Methods and Rebinning Sizes on the Modulation Transfer Function of a Mammography Systems}

\begin{abstract}
In this study, the image quality of the mammography system was measured by mathematical methods. New methods for performance measurements have been used to quantitatively evaluate the image quality in mammography systems. Since the quantitative evaluation of imaging quality gives more objective results than evaluation of visual, numerical evaluations have been emphasized within the scope of the study. The Slanted-edge method was used for the calculation of modulation transfer function (MTF), and angular calculations were made in the use of this method. On effect of different region-of-interest (ROI) selection on edge spread function (ESF), use of different differentiation methods for line spread function (LSF), MTF, and on the effect of different rebinning sizes on ESF, LSF and MTF were investigated. All these methods consist of the calculation were designed to perform using the MATLAB program.
\end{abstract}

Key words: Mammography systems, Image quality evaluation, Modulation transfer function, MATLAB 


\section{Giriş}

Sayısal radyolojik sistemlerde görüntü kalitesini birçok faktör etkilemektedir. X-1şın spektrumu (demet enerjisi ve x-1şın şiddeti), ışınlama geometrisi, odak noktası ve büyütme faktörleri, saçılan 1şınlar, farklı dedektör yapıları (dolaylı ve dolaysız sistemler) ve sistemlerin elektronik yapısından kaynaklı etkenler bunların bir kısmıdır. Görüntü kalite testlerinin değerlendirmesinde kullanılan yöntemler ikiye ayrılmaktadır. Bunlardan ilki görüntü kalitesinin görsel olarak değerlendirilmesi, ikincisi ise görüntü kalitesinin sayısal olarak değerlendirilmesidir [1].

Görüntü kalitesini görsel olarak değerlendirmek için yüksek kontrast uzaysal ayırma gücü, düşük kontrast ayırma gücü ve kontrast ayrıntı ölçümleri gibi yöntemler kullanılmaktadır. Bu yöntemler için tasarlanmış birçok fantom ile görüntü kalitesi testleri görsel olarak yapılabilir. Görsel değerlendirme için çeşitli test fantomları geliştirilmiştir. Yüksek obje kontrastına sahip objeleri ayırt edebilme gücü, yüksek kontrastta farklı uzaklıklarda çizgi çiftlerinden oluşan bir fantom (ör. Huttner) kullanılarak belirlenebilir. Düşük kontrasttaki objeleri ayırma gücünü belirlemek içinse farklı kontrast seviyelerinde bölgeler içeren (ör. Low contrast detail detectability LCDD) bir deney fantomuna ihtiyaç vardır. Görüntülenebilen eşik kontrast testleri için farklı boyut ve obje kontrastında yapılar içeren detaylı test objeleri kullanılabilir (ör. Contrast-detail phantom - CDRAD, CDMAM) [2,3].

Görsel değerlendirme, sayısal değerlendirmeye göre daha basit ölçümlerle yapılabilir. Ancak, görsel değerlendirme sonuçları değerlendiren kişilere bağımlılığı ve sayısal hesaplamalar yoluyla elde edilmediğinden, daha sübjektif sonuçlar vermektedir. Sayısal radyolojik sistemlerinde ayırma gücü, görüntüde birbirlerine çok yakın objelerin ayırt edilebilme özelliğidir. Ayırma gücü görüntüdeki iki ayrı noktayı ayırabilme yeteneği olması, milimetredeki çizgi çifti sayısı olarak tanımlanabilir [2]. Ayırma gücü bu gibi görsel değerlendirmelerle ifade edilebildiği gibi ayrıca bir sistemi ayırma gücünü yarı yükseklikteki tam genişlik (YYTG) ve MTF (Modülasyon transfer fonksiyonu) ile sayısal olarak değerlendirmek mümkündür [3-7].

Görüntüleme sistemlerinde ayırma gücünün ölçülmesinde sıklıkla kullanılan sayısal değerlendirme yöntemi MTF' dir ve sistemin frekans ortamında ayırma gücünü belirleyen bir dağılımdır [7]. Bir görüntüleme siteminin girişine aynı genlikte fakat farklı frekanslarda bir giriş sinyali uygulandığında, sistemin çıkışında elde edilen bilginin genliği yüksek frekanslara gidildikçe düşer. Böylelikle sistemin belirlenen bir seviye üzerinde (gürültü seviyesinin üzerinde) çıkış verdiği bir frekans sınıra ulaşılmaktadır. Bu frekans, sistemin ayırma gücü sınırıdır ve Nyquist frekansı ile ifade edilir $[1,8,9]$.

Görüntüleme sistemlerinde, Nyquist frekansı üzerindeki bilgiler görüntülenmemektedir. $\mathrm{Bu}$ durumda, görüntüde bu frekanstan yüksek frekansta yer alan bilgiler, daha düşük frekanslar değerlerinde katlamalar (aliasing) oluşturmaktadır [8]. Görüntülerde, Nyquist frekansından yüksek frekanstaki bilgiler doğrudan alınamıyorsa uygun deney geometrisi ve yöntemler kullanılarak dedektörde yüksek frekans bilgilerin alınması mümkündür. MTF' in pratik olarak ölçülmesi için çeşitli ölçüm geometrileri kullanılabilir. Yarık fantomu görüntüsü metodu, çizgi desen fantom metodu ve kenar görüntüleme metodu en çok bilinen metotların arasındadır $[7,8]$. 
$\mathrm{Bu}$ çalışmada kenar görüntüleme metodu kullanılmıştır. $\mathrm{Bu}$ metotta ilk olarak, görüntüdeki kenarın tespit edilmesi ve açısının bulunması gerekmektedir. Kenar tespiti ve kenar açısı bulunması için birçok yöntem mevcuttur. Bunlardan bazıları açılı kenara bir doğrunun çakıştırılması, kenar açısının eğim hesabı, Hough dönüşümü, Radon dönüşümü olarak sıralanabilir. Farklı yöntemler denendikten sonra bu çalışmada kullanılmak üzere Hough dönüşümü seçilmiştir [10,11]. Hough dönüşümü, matematiksel olarak ifade edilebilen tüm şekillerde kullanılabilen ve sayısal görüntü işlemede şekillerin varlığının, yerinin, kenar açılarının bulunmasında tercih edilen bir dönüşüm yöntemidir [11].

Kenar görüntüleme metodunda öncelikle açı bilgisi kullanılarak daha sık örneklenmiş ESF (Kenar dağılım fonksiyonu) oluşturulur. ESF' in türevi alınarak LSF (Çizgisel dağılım fonksiyonu) bulunur [7]. LSF, sistemin farklı frekanslardaki giriş sinyallerine tepkisi ile ilgili bilgiyi zaman uzayında gösterir. LSF' in fourier dönüşümü alınarak, frekans ortamında ayırma gücünü belirleyen bir parametre olan MTF elde edilmektedir $[1,3,12]$. Anlatılan bu yöntemlerin detayları materyal ve yöntem kısmında bahsedilmiştir.

Görüntü kalitesinin sayısal değerlendirilebilmesi için zaman uzayında kontrast ve sinyal gürültü oranı ölçümleri, frekans uzayında ayırma gücünün ifadesi olan MTF sistemin görüntü kalitesini gösteren ifadelerdendir [7].Bu çalışmanın amacı yukarıda bahsi geçen ve sayısal radyolojik görüntüleme sistemleri için sık kullanılan kalite kontrol yöntemlerini tasarlamaktır.

Literatürde radyolojik sistemlerde, farklı sistemler için görüntü kalitesi testleri yapılmıştır. $\mathrm{Bu}$ testlerde $\mathrm{OBJ}$ gibi hazır paket programlar kullanılmıştır $[1,3,12]$. Bu programlar kalite kontrol çalışmalarında sıklıkla kullanılmakla birlikte özellikle OBJ programında görüntü kalitesi algoritmalarının uygulama detayları bilinmediği gibi algoritma parametrelerinin değiştirilmesi konusunda da çeşitli kısıtlamalar mevcuttur. Belli ölçütleri hesaplayabilmek için farklı yazılımların kullanılması zorunluluğu, bu programların çıkışlarının karşılaştırılması isteği, çıktılar arası uyumluluk, değerlendirme sürecinin uzaması gibi etkenlerden dolayı görüntü kalitesinin değerlendirmesi bu çalışma bünyesinde değerlendirilmiştir.

\section{Materyal ve Metot}

Çalışma kapsamında, GE marka mamografi sistemi (x-1şın jeneratörü 22-49 kVp, X-1şın tüpü Ge MDR, Dedektör özellikleri CsI $24 \times 30.7 \mathrm{~mm}$, piksel boyutu $0.094 \mathrm{~mm}$ ) kullanılmıştır. Mamografi sisteminden alınan görüntü dijital veri formatı olan DICOM (Digital Imaging and Communications in Medicine) formatındadır. Bu görüntünün alındığı mamografi cihazının sistem parametreleri Tablo 1'de verilmiştir.

Tablo 1. Mamografi sisteminden alınan görüntüleme parametreleri

\begin{tabular}{cccc}
\hline $\begin{array}{c}\text { Kullanılan } \\
\text { Görüntüler }\end{array}$ & Özellikleri & $\mathbf{k V p}$ & mAs \\
\hline Kenar Görüntüsü & data_MAM & 29 & 40 \\
\hline
\end{tabular}

Görüntüleme sistemlerinden elde edilen dedektör sinyalinin, dedektör girişine gelen 1şınlama değeri bazı sistemlerde doğrusal davranış bazılarında ise logaritmik davranış göstermektedir. Böylelikle sistemlerin doz-piksel değeri karakteristik eğrilerinden yararlanılarak görüntülerdeki piksel değerlerinden doza geçilir. Dedektör yanıtları 
logaritmik davranış gösteren sistemlere bu doz-piksel karakteristik eğrisi değerlerinden yararlanılarak doğrusal hale getirme işlemi ile STP düzeltmeleri yapıldıktan sonra sayısal değerlendirmeler yapılmalıdır [1]. Bu çalışmada kullanılan sistemin dedektör yanıtı doğrusal davranış göstermektedir.

\subsection{Modülasyon transfer fonksiyonun hesaplanmast}

Uluslararası standartlara uygun şekilde boyutlandırılan kenar görüntüsünün ilk olarak görüntüden seçilen ilgili alan oluşturularak açı değeri Hough dönüşümü ile bulunmuş, kenar görüntüdeki, kenara dik düzlemdeki her satır için konumlarının piksel değerleri, piksellerin kenardaki dik uzaklıklarına $(\mathrm{mm})$ karşı daha sık örneklenme işlemi yapılarak çizdirilmiștir. ESF' in türevi alınarak LSF olușturulmus daha sonra da LSF' in fourier dönüşümü alınarak MTF elde edilmiştir [1,7,11]. Bu işlemler Şekil 1'de akış şeması olarak verilmiştir.

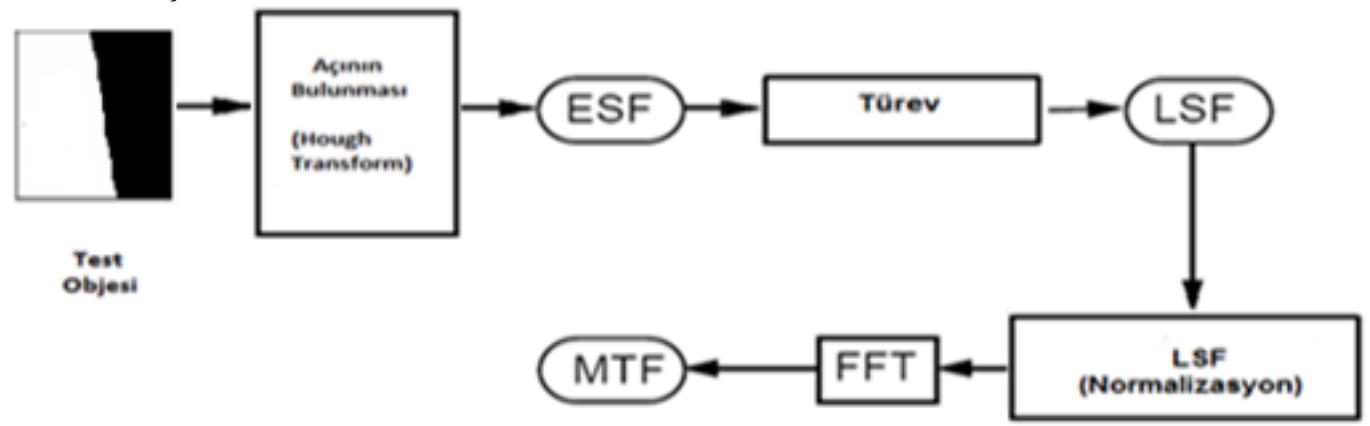

Şekil 1. Modülasyon transfer fonksiyonu akış diyagramı

\subsubsection{Kenar görüntüsünün elde edilmesi}

Çalışma kapsamında, kenar görüntüleme metodu için kullanılan görüntüler IEC 622201 (International Electrotechnical Comission) standardında tavsiye edilen yönteme uygun olmasına dikkat edilmiştir. Ayrıca elde edilen kenar görüntülerin değerlendirme aşamasındaki ilgi alan seçimi yine bu standarda göre yapılmasına dikkat edilmiştir. Şekil 2'de seçilen ilgi alanı için $(b=50 \mathrm{~mm}, \mathrm{c}=100 \mathrm{~mm})$ ve kullanılan tungsten ve kurşun plakalar için $(\mathrm{a}=200 \mathrm{~mm}, \mathrm{~d}=70 \mathrm{~mm}, \mathrm{e}=90 \mathrm{~mm}, \mathrm{f}=100 \mathrm{~mm})$ tavsiyeler yer almaktadir [4].
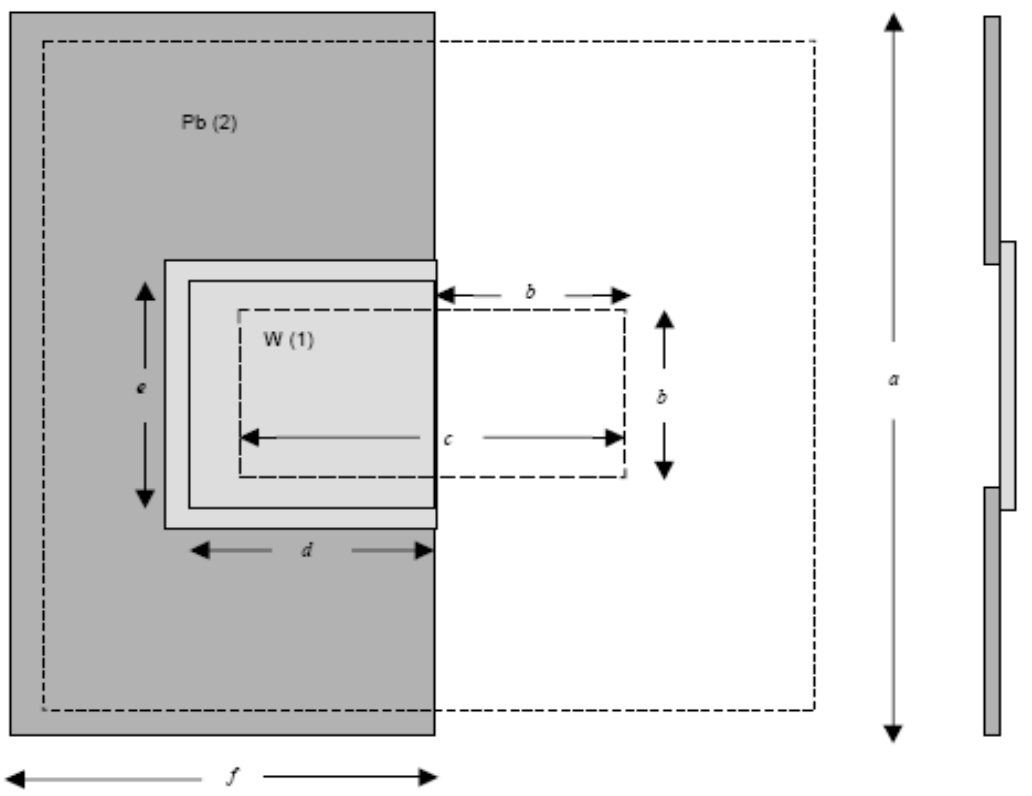

Şekil 2. IEC 62220-1 standardına göre kenar görüntüsü örneği (IEC 2003) 


\subsubsection{Kenar açısının hesaplanmast}

İlk olarak mamografi sisteminden elde edilen kenar görüntüsünden farklı ilgi alan seçilmiştir (Tablo 2.). İstenilen ilgi alanı seçildikten sonra Hough dönüşümü ile kenar açısı tespiti yapılmıştır. Bu uygulamada kenar belirleme işleminde Canny filtresi kullanılmıştır. Canny filtresi görüntüye uygulanmış ve kenarlar tespit edilmiştir. Daha sonra Hough dönüşümü kullanılarak yapılan kenar tespitinde bir eşikleme yöntemi ile görüntü siyah-beyaz hale getirilir. Her kenar pikseli için noktanın üzerinde olabileceği geometrik şekillerin polar koordinattaki değerleri kullanılan bir akümülatör matrisi oluşmuş olur. Akümülatör matrisi üzerinde birer artırılarak her kenar pikselin olası şekilleri belirlenmesi sağlanmış olur. Akümülatör değeri en yüksek olan şekiller en çok belirgin olanlardır. Görüntü üzerinde bulunma veya belirgin olma olasılıkları en yüksek olanlardir [11].

Akümülatör değeri yüksek olan şekiller isteğe bağlı olarak görüntü üzerine çizdirilebilmektedir. Böylelikle görüntüdeki kenar bilgisinin eğimi sayesinde görüntünün eğim açısı hesaplanmıştır. Çalışma kapsamında farklı hassasiyette açı hesaplamaları denenmiş denenen değerler arasındaki fark \%0,9 olduğundan dolayı OBJ programıyla uyumlu (uygun hassasiyetli) açı değeri Tablo 2'de gösterilmiştir.

\subsubsection{Kenar dağılım fonksiyonun hesaplanması}

Bir kenar görüntüsünün herhangi bir satırdan profil alınarak o satırın ESF' in bilgisi elde edilebilmektedir. Ancak tüm görüntüden ya da seçilen ilgi alanından kenar bilgisinin daha detaylı elde edilebilmesi için birden fazla satır bilgisine ihtiyaç duyulmaktadır. $\mathrm{Bu}$ yüzden tüm görüntüden elde edilen ESF' $\mathrm{i}$ elde etmek daha anlamlidir.

Birden fazla satır kullanılması durumunda kesitlerin birleştirilebilmeleri için piksellerin kenara olan uzaklıkları kullanılır. Denklem 1'de kenardan olan uzaklık, $(s(i, j)=p(j \cos \alpha$ $i \sin \alpha)$ ), piksellerin seçilen ilgili alanında kenardan $i$. satıra olan mesafeleri bulunarak gerçekleştirilir. Ayrıca görüntüdeki piksel boyutu hesaplamada kullanılmaktadır [7].

$$
E_{j}^{i}=\int E S F(s) \delta(s+i p \sin \theta-j p \cos \theta) d s
$$

Burada, p piksel boyutu, i satır sayısı, j kolon sayısıdır.

$\mathrm{Bu}$ uzaklıklar bir önceki aşamada bulunan açı değeri kullanılarak bir koordinat dönüşümü olarak ifade edilebilir. Bu yöntem kullanılarak belirlenen kenar açısıyla piksellerin yeni koordinatları hesaplanmıştır (Şekil 3).

Yeni oluşan koordinatlar aşağıdaki ilişkiye bağımlıdır.

$$
\begin{aligned}
& x k r d=x \cos \theta+y \sin \theta \\
& y k r d=y \cos \theta-x \sin \theta
\end{aligned}
$$




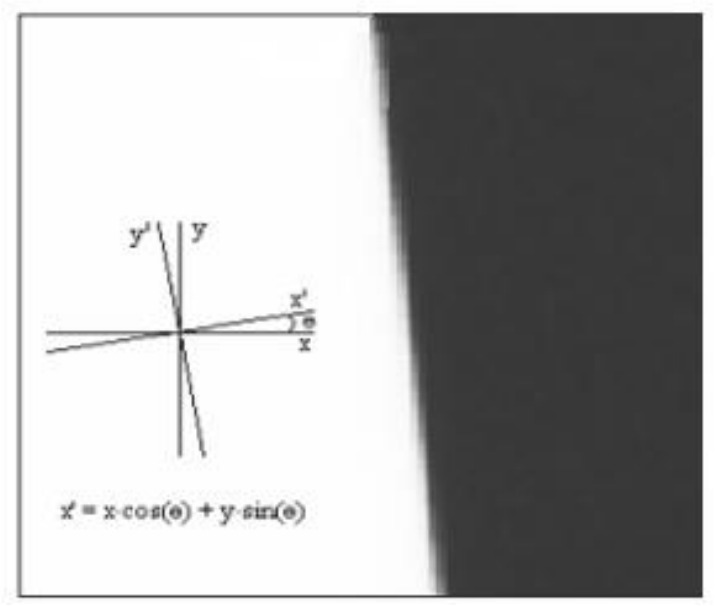

Şekil 3. Koordinatları değişen kenar görüntü

Denklem 3' de ESF hesabında, kenar bilgisini daha detaylı elde etmek için farklı ince gruplama boyutunda, piksellerin mesafe bilgisinin aralıkları daha da daraltılarak ince gruplama işlemi yapılır [7].

$$
E S F_{k}=\frac{1}{n_{k}} \sum_{i j} E_{i j} \operatorname{bin}(s(i, j)-k \Delta s)
$$

\subsection{4 Çizgisel dă̆ılım fonksiyonun hesaplanması}

LSF, daha sık örneklenerek oluşan ESF' in türevi alınarak oluşturulmuştur. Oluşturulan LSF sıfir frekans değerine normalize edilir (Şekil 4). Uygulanan yöntem Denklem 4'de belirtilmiştir [7].

$$
L S F=\left\{\frac{d}{d x}[\operatorname{esf}(x)]\right\}
$$

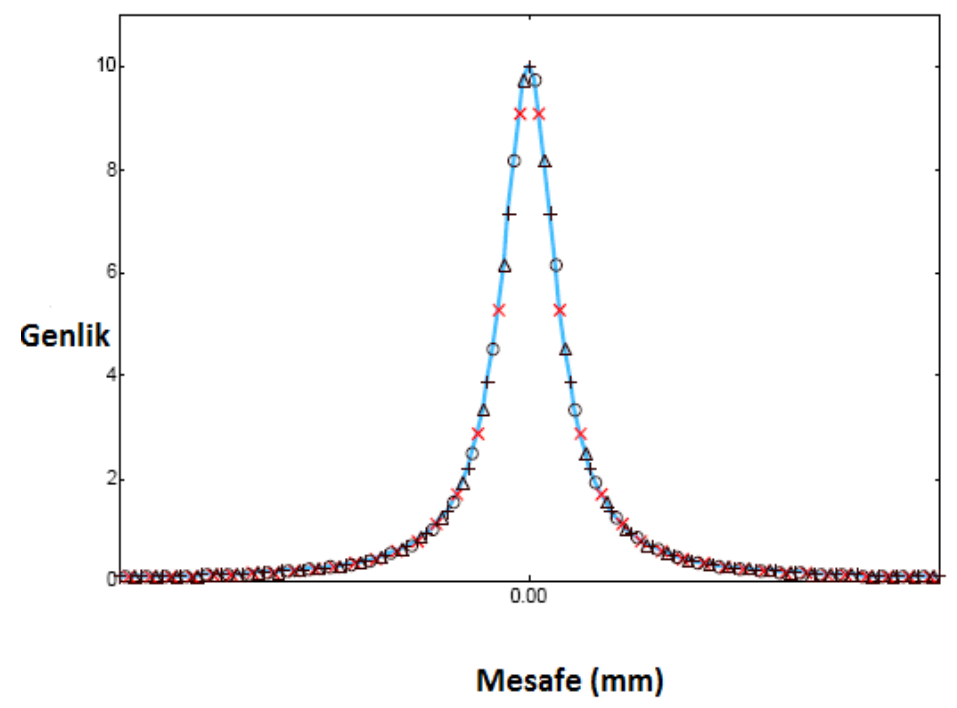

Şekil 4. Yüksek çözünürlüklü kenar dağılım fonksiyonu 


\subsubsection{Fourier dönüşümü kullanılarak modülasyon transfer fonksiyonun hesaplanmast}

Denklem 5' de LSF' in fourier dönüşümü alınarak elde edilen MTF değerleri sıfır frekanstaki değerlere bölünerek normalize edilir. Böylelikle frekans uzayında ayırma gücünü belirleyen bir parametre olan MTF elde edilir [7].

$$
\operatorname{MTF}(f x, 0)=F T\{\operatorname{LSF}(x)\}
$$

\section{Bulgular}

\subsection{Açı hesaplamalarının karşılaştırılması}

Çalışma kapsamında data_MAM olarak adlandırılan görüntü kullanılmıştır. MTF ölçülmesinde kenar metodu yöntemi uygulanmıştır[1, 7]. Bunun için 0,8 mm kalınlığında bir çelik plaka, ince örneklenmiş çizgi dağılım fonksiyonunun elde edilmesi için katot - anot eksenine yaklaşık 6 derece açı ile dedektör üzerine koyularak görüntülenmiştir. Tasarlanan algoritma ile OBJ' de hesaplanan açı değeri sonuçları Tablo 2'de gösterilmektedir. Algoritmalardan hesaplanan açı değerleri ile OBJ yazılımı ile karşılaştırıldığında aralarındaki fark \% 0.9 olarak bulunmuştur. Ayrıca OBJ programında, sadece kare ilgi alanları seçimi yapılabildiği, eşit olmayan ilgi alan seçilerinin yapılamadığından dolayı o değerlere ait açı hesapları Tablo 2'de verilememektedir.

Tablo 2. Farklı ilgi alan seçimlerinde açı karşılaştırılmaları

\begin{tabular}{cccc}
\hline \multirow{2}{*}{ ROI (mm) } & \multicolumn{3}{c}{ data_MAM $\left(\mathbf{a c ̧}^{\circ} \mathbf{)}\right)$} \\
\cline { 2 - 4 } & Matlab & OBJ & \% Fark \\
\hline $40 \times 40$ & 6.52 & 6.58 & 0.9 \\
$30 \times 30$ & 6.53 & 6.59 & 0.9 \\
$100 \times 50$ & 6.59 & - & - \\
$80 \times 40$ & 6.59 & - & - \\
$60 \times 30$ & 6.50 & - & - \\
\hline
\end{tabular}

3.2 Farklı ilgi alan seçimlerinin kenar dağılım fonksiyonu üzerine etkilerinin incelenmesi

Görüntüden elde edilen (data_MAM) elde edilen ESF' ler farklı ilgi alanlarında elde edilen sonuçlar Şekil 5'de gösterilmiştir. 


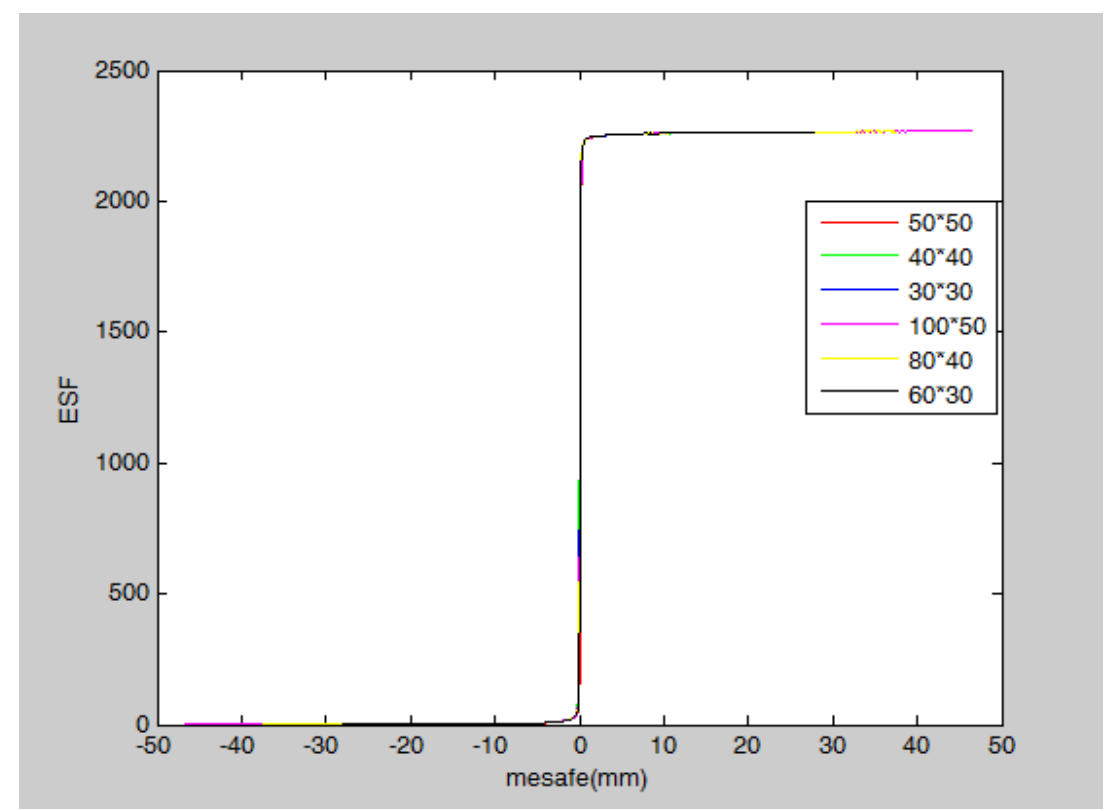

Şekil 5. data_MAM için farklı ilgi alanlarındaki kenar dağılım fonksiyonları

\subsection{Farklı türev seçimlerinin çizgisel dağılım fonksiyonu ve modülasyon transfer} fonksiyonu üzerine etkilerinin incelenmesi

Deney görüntüsü data_MAM farklı türev operasyonlarının LSF ve MTF üzerindeki etkileri incelenmiştir (Şekil 6 - 7). Türev operasyonlarından ilki ardışık iki nokta arası türev işlemi (türev1), ikincisi ise bir atlamalı iki nokta arası türev işlemidir (türev2). Bu farklı türev işlemleri gerçekleştirilen algoritmalar çıktıları OBJ programıyla karşılaştırılmıştır.

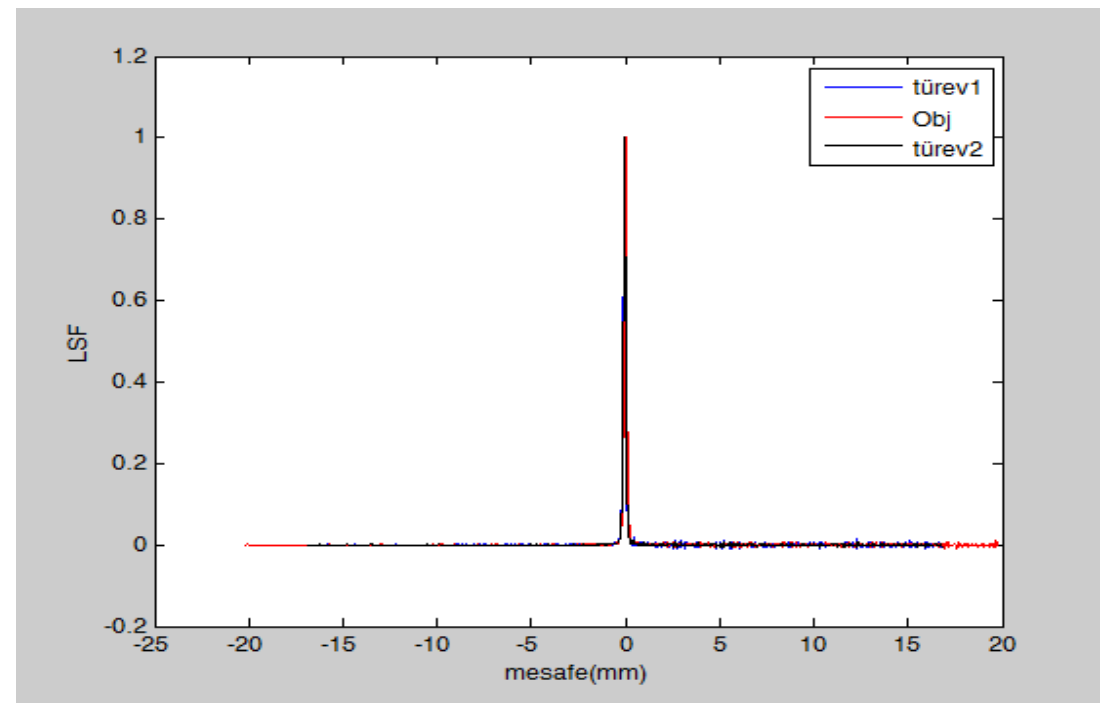

Şekil 6. data_MAM için farklı türev seçimlerinde çizgisel dağılım fonksiyonları 


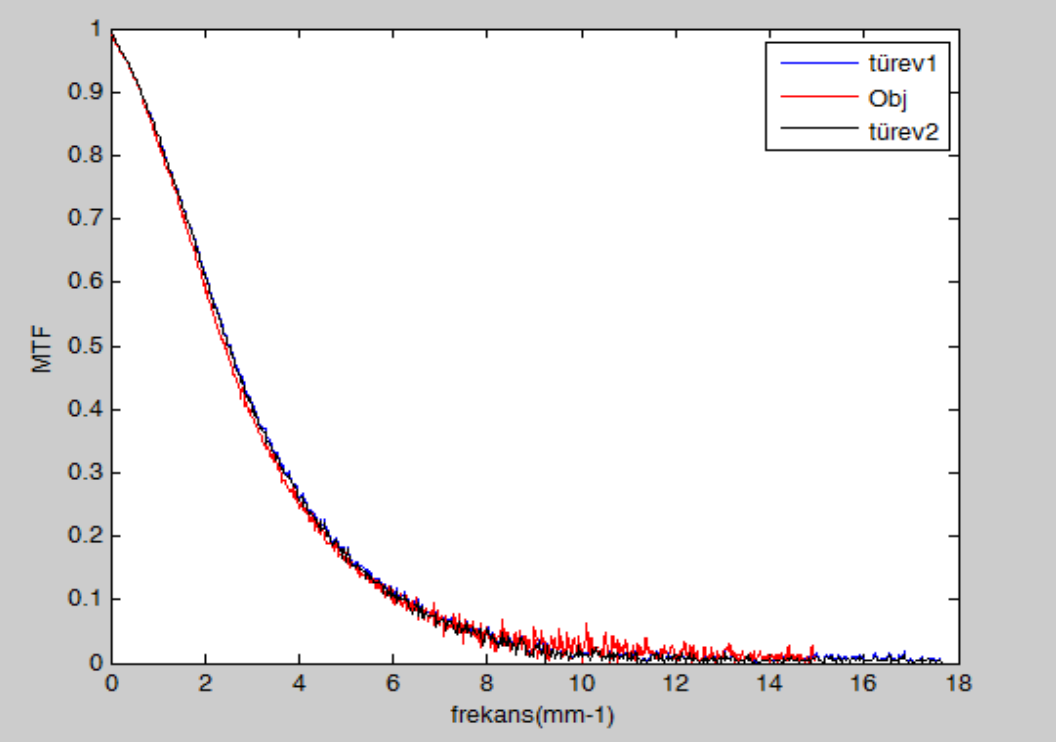

Şekil 7. data_MAM için farklı türev seçimlerinde modülasyon transfer fonksiyonları

\subsection{Farklı ince gruplama kullanımlarının kenar dağılım fonksiyonu, çizgisel dă̆ılım fonksiyonu ve modülasyon transfer fonksiyonu üzerine etkileri}

$\mathrm{Bu}$ kısımda farklı ince gruplama değerlerinde data_MAM görüntüsüne yapılan işlemlerin ESF, LSF ve MTF' e olan etkisi incelenmiştir. Önceki çalışmalarda ince gruplama değerinin 0,1 olarak ayarlanıp sonuçlar elde edilmiş ve bu sonuçlar OBJ programında karşılaştırılmıştır. Bu çalışmada ise ince gruplama değerleri $0.1 ; 0.5 ; 1$ olarak seçilmiş ve sonuçlar kendi aralarında karşılaştırılmıştır (Şekil 8-10).

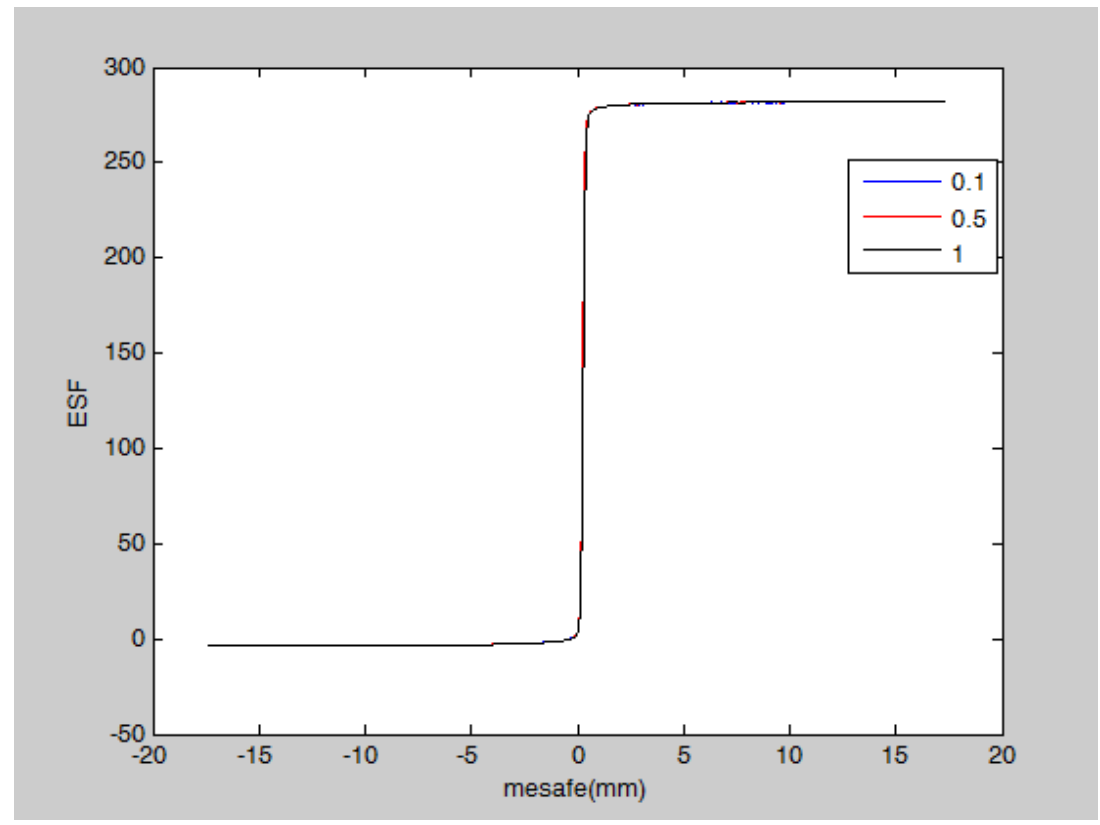

Şekil 8. Farklı ince gruplama seçimlerinde kenar dağılım fonksiyonları 


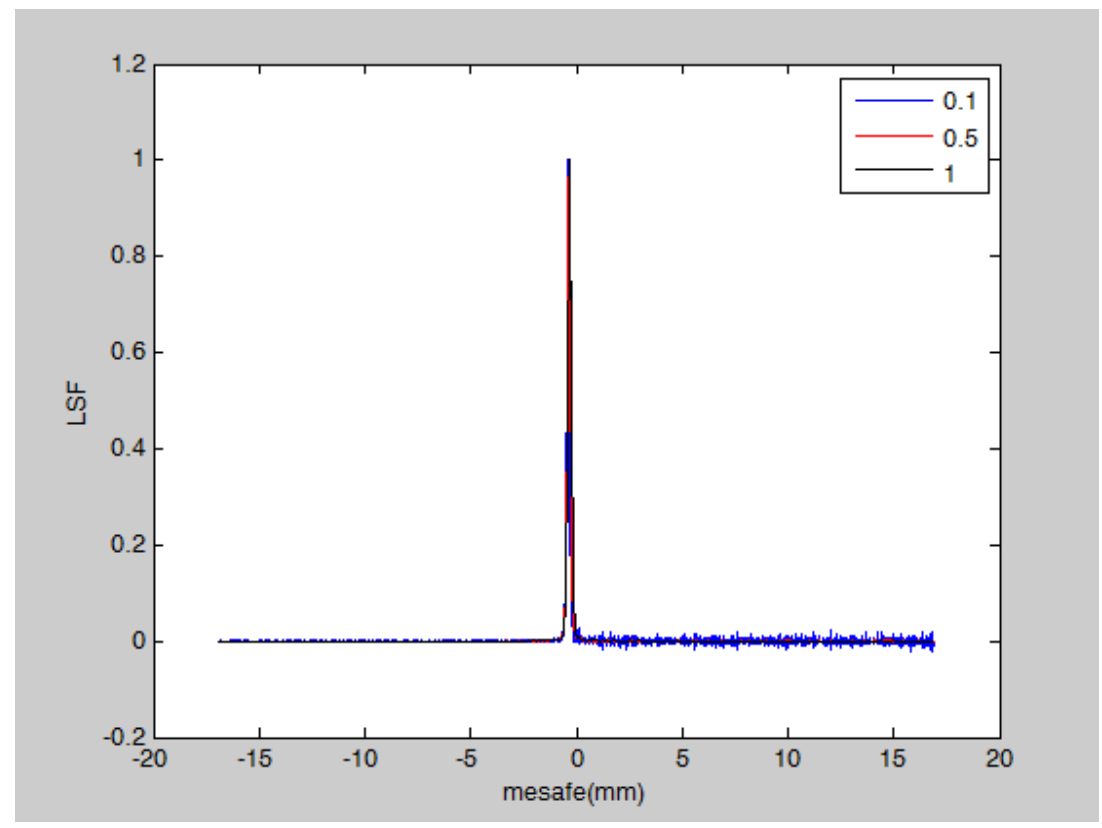

Şekil 9. Farklı ince gruplama seçimlerinde çizgisel dağılım fonksiyonları

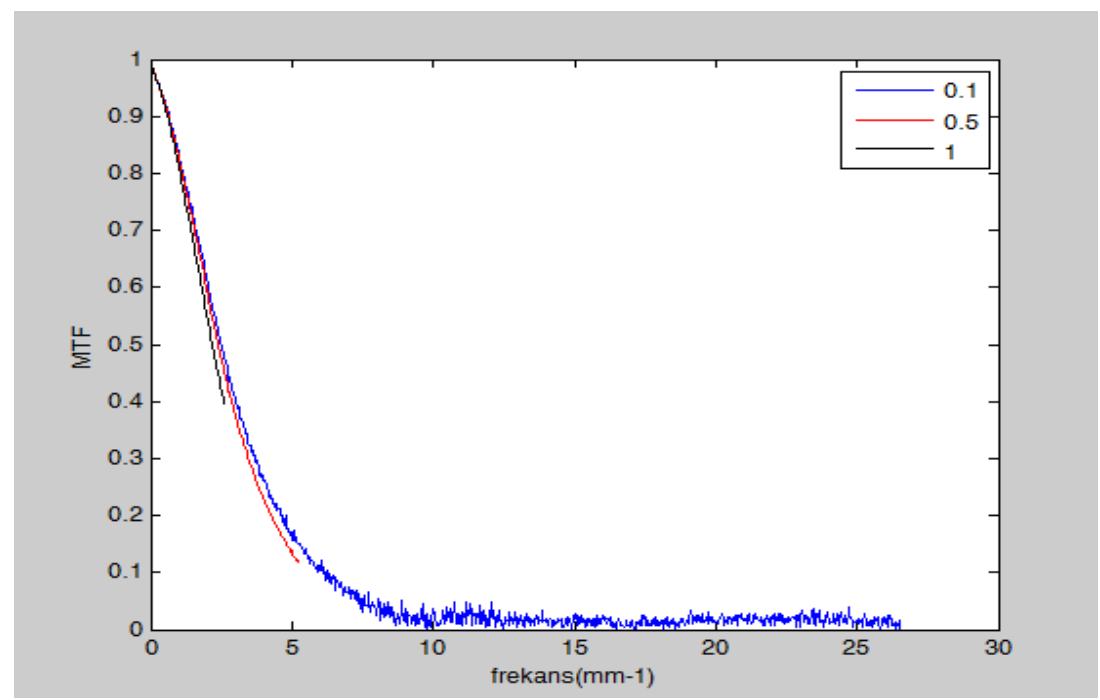

Şekil 10. Farklı ince gruplama seçimlerinde modülasyon transfer fonksiyonları

\section{Sonuç ve Yorum}

Görüntü kalitesinin sayısal değerlendirilmesi, görsel olarak değerlendirmeye göre daha objektif sonuçlar verdiğinden dolayı bu sonuçlar gözlemciye göre değişmemektedir. Ayrıca sayısal yöntemler kullanıldığında pratik ölçüm düzenekleri ile sistemin frekans uzayında performansının belirlenmesi de mümkündür. $\mathrm{Bu}$ nedenlerden dolayı, bu çalışma kapsamında görüntü kalitesinin sayısal olarak değerlendirilmesine odaklanılmıştır. Tüm bu işlemler, IEC standardının parametreleri göz önüne alınarak gerçekleştirilebildiği gibi, gerçekleştirilen algoritmaların esnek yapısı sayesinde araştırma amaçlı olarak farklı parametreler uygulanabilmektedir [4,5].

Görüntü kalitesinin sayısal hesaplamalarında önce, her inceleme için sistemlere uygun STP düzeltmeleri yapılmalıdır. Çalışma kapsamında kullanılan mamografi cihazı doğrusal bir sistemdir. Materyal ve Metot kısminda anlatılan yöntemler, dedektör yanıtları doğrusal davranış gösteren sistemler için geçerlidir. MTF hesaplamalarında 
kenar görüntüleme metodu seçildiği için, ilk önce kenar açısı hesaplanmıştır. Kenar görüntüsünden elde edilen sonuç, OBJ yazılımı ile karşılaştırıldığında sapma \%1'in altında hesaplanmıştır (Tablo 2). OBJ programında, sadece kare ilgi alanları seçimi yapılabildiği için eşit olmayan ilgi alan seçimlerinin yapılamadığından bu çalışmada gerçekleştirilen algoritmaların hareket alanının daha iyi olduğu gösterilmiştir (Tablo 2).

Şekil 5'te farklı ilgi alan seçimlerinde ESF' lerin nasıl değiştiği incelenmiştir. Bu incelemenin yapılma sebebi, farklı kare ilgi alanlarında ve kare dışındaki ilgi alanlarında görüntüdeki düşük frekans bilgisinin (saçılan x-1şın etkilerini) grafiklere olan etkisini gözlemleme isteğidir [13]. Kullanılan veriler için ilgi alan seçimlerine göre grafiklerin genlik değerlerinin değişmediği ancak görüntüdeki piksel değerlerinin, piksellerin kenardan olan uzaklıklarına göre değiştiği gözlenmiştir.

ESF' ten LSF' e geçiş türev işlemiyle sağlanmıştır. Farklı türev yöntemlerinin LSF ve MTF üzerine etkileri, Şekil 6 ve 7' de incelenmiştir. Farklı türev ifadeleri görüntü üzerinde farklı filtreleme etkileri gösterdiğinden, görüntüdeki gürültü seviyesi ve gözlemlenmek istenen etkilerin frekans karakteristiğine göre farklı yöntemler seçilebilir. Nokta atlamalı türevde gürültü etkileri daha iyi bastırılmakla birlikte, saçılma etkileri gibi dar bir frekans aralığında gözlemlenmek istenen yüksek değişim gösteren karakteristikler de filtreleme riskli olabilir.

Çalışma kapsamında gerçekleştirilen algoritmada, MTF' ler, sıfır frekanstaki 1'e normalize edilerek hesaplanmıştır. Şekil 7'de algoritmada elde edilen sonuçlar ile OBJ yazılımından elde edilen sonuçlar ile karşılaştırılmıştır. Sonuçlar, görsel olarak kıyaslanmış ve bu sonuçların tutarlı oldukları görülmüştür. Aynı sistemlerden hesaplanan MTF sonuçlarının birbirine benzer çıkması beklenmektedir. MTF grafikleri, beklendiği gibi bulunmuştur. Şekil 8 ve Şekil $9^{‘}$ de ince gruplama işleminin, ESF ve LSF hesaplamalarına olan etkisi görülmektedir. İnce gruplama aralıkları değiştirilerek ESF ve LSF' ler elde edilebilmektedir. Ancak ince gruplamanın sistem karakteristiğine etkisini, sistemlerin ayırma gücünün ifadesi olan MTF hesabından daha detaylı olarak gözlemlenebilmektedir.

Şekil 10‘de ince gruplama işleminin MTF hesabındaki etkisi açıkça görülmektedir. İnce gruplama işlemi yapılarak, MTF grafiklerinde Nyquist frekansı üzerinde frekanslara sahip bilgilere erişilmeye çalışılmıştır. Herhangi bir ince gruplama işlemi yapılmaması durumunda Nyquist frekansı üzerinde frekanslara sahip bilgilere erişilememektedir. İnce gruplama aralıkları $(0,1 ; 0,5 ; 1)$ değiştirilerek daha dar veya daha geniş frekans aralıklarında kullanılan sistemin karakteristikleri incelenebilmektedir. İnce gruplama aralıkları daraltıldığında, sistem karakteristiğini daha yüksek frekanslarda elde edilebilmekte ancak gürültü artmaktadır.

Literatürde tavsiye edilen ince gruplama değeri 0,1 'dir [7]. İnce gruplama aralıkları daraltıldığında sistem karakteristiğini etkileyen gürültü artışının hesaplamaları etkilememesine dikkat edilmelidir. Böylelikle sistemlerin piksel boyutunun etkisinden bağımsız olarak daha geniş frekans aralığında sistem karakteristiği elde edilmiş olur. Şekil 10'e göre daha yüksek ince gruplama değeri ile de kesim frekansina kadar karakteristiğin elde edilebileceği böylelikle daha az gürültülü MTF hesaplanabilir. Çalışmadaki tüm grafikler incelendiğinde OBJ yazılımından elde edilen grafiklerde gürültü giderici algoritmalar kullanıldığ 1 tahmin edilmektedir. Ayrıca literatürde gürültü gidermek için çeşitli yöntemler MTF hesaplamalarında kullanılmaktadır. Örneğin ESF verilerini gaussian ağırlıklı polinoma fit edilmesi [11,13], median filtrelenmesi [3], 
ESF' lerin verilerini çeşitli polinomlara fit ederek daha yumuşak hale getirmek gibi çeşitli yöntemler kullanılmaktadır [8,9].

Sonuç olarak, literatürdeki görüntü kalitesi metrikleri için farklı algoritmalar denenerek mamografi sisteminde görüntü kalitesi sayısal olarak değerlendirilmiştir. Bu değerlendirme işlemleri; farklı ilgi alanlarında, türev ve ince gruplama seçimlerinde MTF 'lere etkileri araştırılmıştır. Yukarıda bahsi geçen gürültü giderici yöntemler, ham verileri etkileme ve araştırma faaliyetlerinde kullanılması ihtimalinden dolayı kullanılmamıştır. Gelecekte geliştirilecek yazılım ve/veya yazılımlar araştırma faaliyetlerinde kullanılabilir nitelikte olup, bu altyapı kullanılarak radyoloji sistemlerindeki kalite kontrol hesaplamalarına alternatif algoritmalar eklenebilecektir.

\section{Araştırmacıların Katkı Oranı Beyanı}

Yiğit Ali Üncü: Araştırma, Metodoloji, Yazılım, Kaynak/Materyal/Malzeme Temini

Hasan Özdoğan: Yazılım, Veri İyileştirme, Orijinal Taslak Yazımı

\section{Destek ve Teşekkür Beyanı}

Bu çalışma Yiğit Ali Üncü' nün yüksek lisans tezinden türetilmiştir. Yazarlar olarak, tez çalışmasının yürütülmesi sırasındaki katkılarından dolayı Dr. Özlem BİRGÜL' e teşekkürü borç biliriz.

\section{Çatışma Beyanı}

$\mathrm{Bu}$ çalışmanın yazarları olarak herhangi bir çatı̧̧ma beyanımız bulunmadığını bildiririz.

\section{Etik Kurul Onayı ve/veya Aydınlatılmış Onam Bilgileri}

$\mathrm{Bu}$ çalışmanın yazarları olarak herhangi bir etik kurul onayı ve/veya aydınlatılmış onam bilgileri beyanımız bulunmadığını bildiririz.

\section{Kaynakça}

[1] N. W. Marshall, "A comparison between objective and subjective image quality measurements for a full field digital mammography system," Phys. Med. Biol., 51 (10), 2441, 2006.

[2] A. Pascoal, C. P. Lawinski, I. Honey, and P. Blake, "Evaluation of a software package for automated quality assessment of contrast detail images - Comparison with subjective visual assessment," Phys. Med. Biol., 50 (23), 5743, 2005.

[3] N. W. Marshall, "Early experience in the use of quantitative image quality measurements for the quality assurance of full field digital mammography x-ray systems," Phys. Med. Biol., 52 (18), 5545, 2007.

[4] International Electrotechnical Commision., IEC, and Din, "Medical electrical equipment Characteristics of digital X-ray imaging devices - Part 1: Determination of the detective quantum efficiency," 2003.

[5] International Electrotechnical Commission, "62220-1-1:2015 Medical electrical equipment Characteristics of digital X-ray imaging devices - Part 1-1: Determination of the detective quantum efficiency - Detectors used in radiographic imaging," 2015.

[6] A. K. Carton et al., "Validation of MTF measurement for digital mammography quality control," Med. Phys., 32 (6Part1), 1684-1695, 2005.

[7] E. Samei, M. J. Flynn, and D. A. Reimann, "A method for measuring the presampled MTF of digital radiographic systems using an edge test device," Med. Phys., 25 (1), 102-113, 1998.

[8] E. Buhr, S. Günther-Kohfahl, and U. Neitzel, "Accuracy of a simple method for deriving the presampled modulation transfer function of a digital radiographic system from an edge image," Med. Phys., 30 (9), 2323-2331, 2003.

[9] E. Samei and M. J. Flynn, "An experimental comparison of detector performance for direct and indirect digital radiography systems," Med. Phys., 30 (4), 608-622, 2003.

[10] J. Scharcanski and A. N. Venetsanopoulos, "Edge detection of color images using directional operators," IEEE Trans. Circuits Syst. Video Technol., 7 (2), 397-401, 1997.

[11] E. Samei, N. T. Ranger, J. T. Dobbins, and Y. Chen, "Intercomparison of methods for image quality characterization. I. Modulation transfer function," Med. Phys., 33 (5), 1454-1465, 2006.

[12] N. W. Marshall, "An examination of automatic exposure control regimes for two digital radiography 
systems," Phys. Med. Biol., 54 (15), 4645, 2009.

[13] J. R. Wells and J. T. Dobbins, "Estimation of the two-dimensional presampled modulation transfer function of digital radiography devices using one-dimensional test objects," Med. Phys., 39 (10), 6148-6160, 2012. 